\title{
1 The Changing Health Needs of the UK Population
}

2

3

4

Martin McKee, ${ }^{a}$ Ruth Hussey, ${ }^{\text {a }}$ Karen Dunnell, ${ }^{\text {a }}$ Michael Anderson, ${ }^{b}$ Carol Brayne, Anita Charlesworth, Charlotte Johnston-Webber, Martin Knapp, Ali McGuire, John Newton, David Taylor, Richard G Watt

a. Working Group leads are joint lead authors.

b. The remaining co-authors contributed equally and are listed alphabetically.

\section{Abstract}

The demographics of the UK population are changing, and so is the need for healthcare. In this paper we explore the current health of the population, changing health needs and future threats which lie ahead. Relative to other high-income countries the UK is lagging behind on many health outcomes such as life expectancy and infant mortality, and there is a growing burden of mental illness. Successes exist such as dramatic improvements in oral health, although inequalities are present. The growth of the ageing population relative to the working age population, the rise in people with multimorbidity and persistent health inequalities, particularly for preventable illness, are all issues which will face the NHS in the years to come. Meeting the challenges of the future will require an increased focus on health promotion and disease prevention, involving a more concerted effort to understand and tackle the multiple social, environmental and economic factors which lie at the heart of health inequalities. The immediate priority of the NHS will be to mitigate the wider and long-term health consequences of the COVID-19 pandemic, but it must also strengthen its resilience to reduce the impact of other threats to health, such as the UK leaving the European Union, climate change and antimicrobial resistance.

\section{Introduction}


The NHS has adapted over time to many changing health needs and to advances in the technical and organisational ability to address them. These include major declines in and changing nature of infectious diseases and rising importance of non-communicable diseases. Paediatric wards are no longer full of children with gastroenteritis, respiratory infections, and hepatitis $A$, and now provide specialised neonatal, genetic, and chronic disease services, among others. ${ }^{1}$ Innovations in management of mental health and resulting reconfiguration of services such as the closure of longstay institutions have completely altered treatment pathways, with both positive and negative results. Cardio-thoracic surgeons now rarely dilate mitral valves damaged by rheumatic heart disease, or resect tuberculous lung cavities, instead repairing congenital heart disease or performing transplants. Orthopaedic surgeons no longer transplant tendons of children affected by polio, instead replacing arthritic joints among older people. ${ }^{2}$ General practitioners rarely deliver babies in patients' homes but instead contribute clinical expertise to a range of services provided by multiagency teams based in the community. Dentists very rarely provide full dentures for adults and instead concentrate on prevention and provision of restorative care including implants and bridges. ${ }^{3}$ Entirely new clinical careers and specialties have emerged such as specialist nurses, interventional radiologists and palliative care specialists, while geriatricians, managing the complex needs of frail and ageing patients, work alongside a growing number of super-specialists. ${ }^{4}$

International comparative studies, particularly in earlier decades, indicate that the NHS has been relatively good at such adaptations. ${ }^{5}$ Its system of funding manages to avoid many perverse incentives seen in fee-for-service systems that encourage lucrative interventions to persist long after they have become obsolete, and professional associations, such as the Royal Colleges, emphasise maintaining high standards of training and research rather than negotiating terms and conditions as is the case with some of their equivalents elsewhere. However, some would argue that progress has been slow and inadequate in adapting to epidemiological transition (such as in mental health and the rise in dementia) and in adopting research and innovation at pace (such as stroke management). 
relative to what exists in many other countries, but there remain many gaps in the evidence base. A culture of evaluation and audit has been promoted and has developed well in certain areas, especially those supported by systematic national data collection, for example within the national clinical audit programme. ${ }^{6}$ This research capacity is now needed to understand and develop strategies to mitigate against potentially long-lasting physical and mental health impacts of the COVID-19 pandemic. $^{7}$

The goals of a health system were set out in the World Health Report 2000. ${ }^{8}$ They include improving health outcomes, responding to legitimate public expectations, and achieving fair financing. The third of these is addressed elsewhere in the Commission Report. The first and second require an NHS that is cognisant of, and can adapt quickly and flexibly to, the changing needs of the population, based on evidence where this is available and taking steps to generate it where it is not. Subsequent thinking, developed more fully in the WHO Tallinn Charter, ${ }^{9}$ describes mutual relationships between health systems, population health, and economic growth. ${ }^{10}$ Put simply, the goal of society should be to create a health system that promotes better health and, through improved lives, secures economic growth, which in turn secures revenues to support appropriate health care provision for all, as well as associated developments elsewhere, such as in social care. Health and healthcare can therefore be both inputs to and outputs from the economy.

Yet while it seems obvious that a key objective of the NHS should be to maximise the health of the population of the UK to the extent that this is possible for a health system to achieve, this has not always been how its leadership has interpreted its role. The mission of the NHS has in the past been framed as the more limited but potentially more tractable problem of ensuring the provision of high quality and safe health care to all in response to expressed need within available resources. This longstanding mismatch between the need for a service that addresses optimisation of population "health", and a structure organised to cover the "health-care" problem, may well have contributed to the UK's relatively poor performance on health outcomes. 
It is impossible, in a single paper, to provide a comprehensive analysis of the health of the UK population and its implications for the NHS. Consequently, it has been necessary to be somewhat selective. This paper proceeds as follows. It begins with an assessment of the current situation and how it has developed, starting with the most widely used summary measure of the health of the population, life expectancy. It then reviews some areas that have important implications for the NHS. These are mental health, maternal and child health, oral health, an area that has long existed on the margins of the NHS, and the growing challenge of multimorbidity, with major implications for models of service delivery. It continues by looking at three ways in which the health of the population is continuing to change. These are ageing, the composition of the working population, and the burden of disease. The NHS is, in many respects, responding to failures in other areas of policy. Consequently, a third section examines the scope for prevention, including measures to tackle the social determinants of health. Finally, looking ahead, the concluding section examines two of the immediate threats to the NHS, the COVID pandemic and Brexit.

\section{The Health of the Population}

\section{Life Expectancy in the UK}

The health of the population of the UK is now lagging behind that of many comparable countries. Having been in the middle of the range of high-income countries in 1960, life expectancy at birth is now close to the bottom (Figure 1). Since 2010, the earlier rate of increase in life expectancy at birth has slowed markedly. ${ }^{11} \mathrm{~A}$ recent analysis compared life expectancy in England and Wales with 22 other high-income countries. ${ }^{12}$ This showed how England and Wales diverged markedly from the comparator group between 2011 and 2016. This was driven to a similar extent by diverging mortality in working ages and at older ages. While more recent data are lacking for some comparator countries, the situation in the UK now gives substantial cause for concern as there have been continuing increases in death rates in several age groups and regions and the infant mortality rate in 
England and Wales has now risen in each of the 3 years between 2014 and 2017, something that has not happened for over a century. ${ }^{13}$

The reasons why the UK is falling behind other high-income countries have been debated intensely. Some of the decline seems likely to reflect historical trends, in particular the timing of the smoking epidemic, ${ }^{12}$ but there is increasing evidence pointing to a link with the wide-ranging austerity measures since 2010 affecting many areas of public policy. For example, while the explanation for rising infant mortality is disputed, it has been noted that the increase is greatest in the poorest areas. ${ }^{14}$ There have been substantial cuts to funding for local authorities, with resulting social care service reductions that particularly affect older people and those living in poverty. ${ }^{15,16}$ An exceptional surge in numbers of deaths in 2015 also coincided with widespread capacity problems across the NHS, and while the particular strain of influenza circulating that year may have played a role, this seems unlikely to have been the only reason for this particular spike in mortality. ${ }^{17} \mathrm{~A}$ further spike occurred in 2018. Importantly, although the slowing is not unique, being seen in some (but not all) European countries, it has been more pronounced in the UK than elsewhere, and it is not a survival asymptote of maximum life expectancy being reached, as the UK has not achieved the same levels as other comparable high-income countries. Within the UK, when measured by geography or socioeconomic indicators, it is apparent that there is much scope for the health of the most disadvantaged to experience substantial improvements in healthy and disability-free life expectancy. While differences in life expectancy between the richest and poorest people in the UK narrowed during the 2000s, these differences have widened since $2011 .{ }^{18}$ The impact of the COVID-19 pandemic on life expectancy is yet to be determined, but the combination of excess mortality directly attributable to the acute effects of virus, emerging evidence of long-lasting health problems caused by the virus, ${ }^{19}$ and delayed diagnosis of many conditions such as cancer caused by the postponement of screening and reduced access to healthcare services ${ }^{20}$ will likely lead to a sustained reduction in life expectancy in many countries. The knock on effects on the economy, particularly exacerbating existing inequalities, will also have longer-term indirect effects. As the UK 

gap in life expectancy between the UK and other developed nations may grow in the coming years. countries

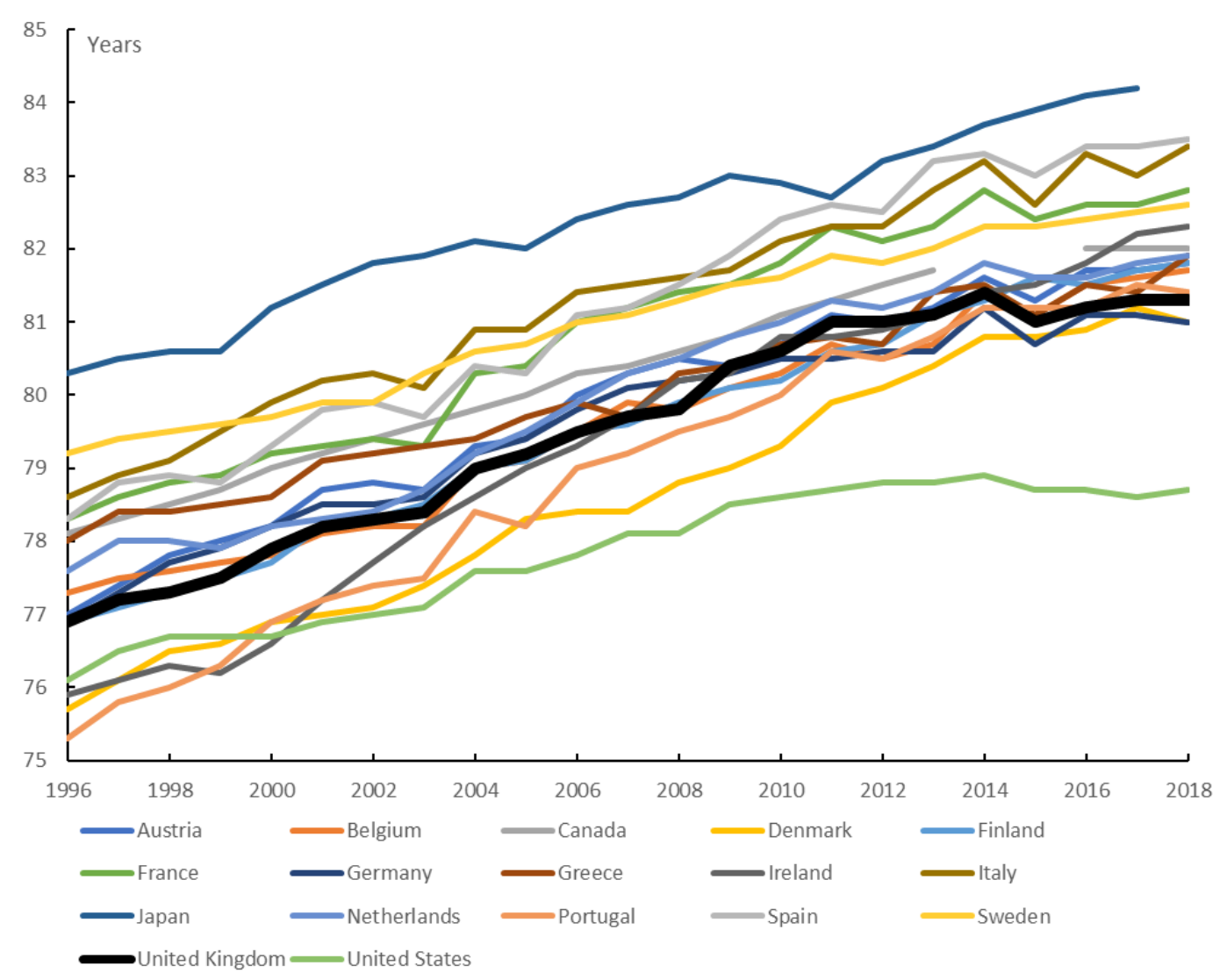

There are also large differences between the four UK nations (Supplementary Material Figure 1). All have experienced a recent slowing of life expectancy at birth. Life expectancy has consistently been higher in England than in the other three nations, with Scotland lagging far behind. Between 1998 and 2018, the gains in life expectancy at birth have been much less among women than men. For example, in England, it increased by 4.3 years but 3.1 among women. In Scotland the gap was even 137 greater, at 4.2 years and 2.7 years respectively. For both sexes these were among the smallest 
among industrialised countries. This is driven, to a considerable extent, by stagnating or falling life expectancy among women aged 75 and above, who have been impacted especially harshly by austerity policies. ${ }^{22}$

Life expectancy is, of course, derived from data on deaths. It can be combined with data on those still alive to generate measures of disability-free life expectancy (DFLE), and healthy life expectancy (HLE). DFLE is an estimate of the number of years lived without a long-lasting physical or mental health condition that limits daily activities. HLE is an estimate of the number of years lived in "Very good" or "Good" general health, based on how individuals perceive their general health. England has the highest life expectancy for both females (83.1) and males (79.6), and Scotland has the lowest life expectancy for both females (81.1) and males (77.0). England has the highest HLE and DFLE for both (Supplementary Material Figure 2).

Within the four nations, there is especially poor health in those areas that have experienced deindustrialisation since the 1980s, such as the west of Scotland, parts of Northern Ireland, South Wales and the North-east and North-west of England. Analysis by geography and deprivation shows that although life expectancy varies by as much as 6 years between the regions of England, most of the difference is accounted for by levels of deprivation. ${ }^{23}$ This analysis also showed that, despite the fact that all the regions of England are subject to broadly similar underlying health policies, regulations and laws, and all are served by the NHS, outcomes such as life expectancy and years lived with a disability in the more prosperous regions of the UK are comparable to those in the best performing advanced high-income countries, such as Sweden and Australia, whereas in the less 
expectancy varies significantly within each UK nation, the consequence being that in many parts of the UK, the average person cannot expect to reach the statutory retirement age in good health. ${ }^{24}$ There are also inequalities among ethnic groups, with estimates suggesting that differences in disability-free life expectancy, at 11.5 years, are twice as large as those in life expectancy. ${ }^{25}$ Chinese men and women have the highest disability-free life expectancy at birth, while Bangladeshi men and Pakistani women have the lowest. The COVID-19 pandemic has exacerbated these health inequalities, particularly for black and minority ethnic groups who have experienced persistently elevated mortality rates from COVID-19. ${ }^{26}$ Differential exposure to coronavirus patterned by occupation and housing conditions, differential severity of COVID-19 patterned by existing health conditions, and differential interactions with the health service, have all been suggested as potential contributory factors. ${ }^{27,28}$

The scale and nature of these differences point to the importance of influences outside the health care system on health outcomes. ${ }^{24}$ The Dahlgren and Whitehead model highlights the potential impact of the wider social determinants of health, such as housing, sanitation, unemployment, education and food production. ${ }^{29}$ Austerity measures adopted since 2010 have had a disproportionate impact on the poor, ${ }^{30}$ creating insecurity of income, employment, housing ${ }^{31}$ and even food supply, as revealed by the growth of foodbanks. ${ }^{32}$ Addressing these social determinants of ill health will require wide-ranging action across many sectors, recognising the need for action at every stage of the human life course, also recognising the role of intergenerational transmission of disadvantage, and risking a downward spiral. ${ }^{33}$ These measures must recognise the concept of intersectionality, whereby some individuals have a combination of characteristics, all of which disadvantage them; and the existence of a health gradient between rich and poor. This points to the need for what is termed proportionate universalism, ${ }^{24}$ where provision of services is universal but measures are taken to increase uptake by those in most need. 
The burden of disease attributable to mental illness, including what are termed common mental illnesses (anxiety, depression, panic disorder, phobias and obsessive compulsive disorder), has been growing over the past 25 years. ${ }^{34}$ The COVID-19 pandemic has also had a profound impact on mental health, with many individuals suffering from anxiety, isolation and difficulties in accessing mental health support. ${ }^{35}$ High-quality data needs to be collected to understand this impact, particularly for vulnerable groups such as older people, young people, people with pre-existing mental health issues, and healthcare workers. ${ }^{36}$ To mitigate against long-term consequences for mental health, supportive measures are needed such as providing widespread access to emergency psychological includes important consequences for the labour-intensive health sector.

The mental health needs of the older population are significant. Although the age-specific prevalence of dementia appears to be decreasing slightly, ${ }^{41}$ population ageing means that the absolute numbers of older adults experiencing cognitive decline due to Alzheimer's or other dementias will rise. Prevalence of dementia increases from one in 14 at the age of 65 to one in six in those over $80 .{ }^{42}$ However, older people's mental health needs do not just relate todementia. Depression is the most common mental health disorder in this age group, with estimates of a prevalence of $22 \%$ in men and $28 \%$ of women aged over 65 , and over $40 \%$ of those in care homes. ${ }^{43}$ There is also a high prevalence of anxiety disorder, ${ }^{44}$ and other disorders such as bipolar disorder and psychosis are less common but nonetheless significant. Research shows that older adults with depression are significantly less likely to be diagnosed and treated than younger adults with the condition, ${ }^{45}$ and there is more generally lack of parity of esteem regarding services and funding for mental health care for older people compared to that for working age adults. ${ }^{46}$ 
There is growing evidence of a high burden of mental illness among British children and adolescents, to the point that the situation has been described as a 'crisis'. ${ }^{47}$ Data from 2017 in England showed that one in eight 5 to 19 year olds had at least one mental illness and that one in twenty met criteria for two or more mental illnesses. ${ }^{48}$ The same data show a gradual increase in mental illness in young people since 1999, with the prevalence increasing with age, particularly on transition to adolescence and secondary school. ${ }^{48}$ Of particular concern is the high level of mental illness in girls aged 17-19. Nearly one in four of this group have a diagnosable mental illness, and over half of these reported self-harming behaviour or suicide attempts. Universities have reported a huge increase in pressure on student mental health services and rising numbers of student suicides, ${ }^{49}$ and research shows an increase in adolescent girls presenting to UK Accident and Emergency departments with self-harm. ${ }^{50}$

The reasons for the increasing burden of mental illness in young people are complex. Social media, the impending threat of environmental catastrophe and political instability, uncertainty about future prospects, higher rates of family breakdown and academic pressure have all been proposed as causative factors. Unrealistic social pressure to excel in all areas of life, promoted by social media and an ethos of consumerism is another toxic, relatively new phenomenon. However, it is crucial to try to address this area of growing need as it is well established that around half of mental illnesses start before the age of 14 and three-quarters are established by the age of $24,{ }^{51}$ particularly because adolescence into young adulthood is a pivotal life-stage for key decisions regarding education, employment and relationships.

The burden of disease due to alcohol and illicit drug use has increased across the UK in recent years. Alcohol-related deaths in the UK increased to an age standardised rate of 12.2 per 100,000 in 2017, which is similar to 2008 when deaths were at the highest recorded levels. ${ }^{52}$ Scotland consistently has the highest rate of alcohol-related deaths in the UK, at 20.5 per 100,000 in 2017, although this has significantly reduced from a peak of 28.5 per 100,000 in $2006 .{ }^{52}$ Drug-related deaths in England and Wales have increased from an age-standardised rate of 42.9 per 1,000,000 in 1993 to 66.1 per $1,000,000$ in $2017 . .^{53}$ In comparison, Scotland's incidence of drug-related deaths is over three times 
the rate in England and Wales at 192.6 per 1,000,000 in 2017, ${ }^{54}$ and the highest recorded drugrelated death rate in the EU. There are also significant inequalities in alcohol and drug-related deaths across the UK, for example over half of the drug-related deaths in Scotland occur in people from the most deprived quintile, ${ }^{55}$ and the rate of alcohol-related deaths is over three times higher in the most deprived quintile than the least deprived quintile in England..$^{56}$ These increases in alcohol and drug-related deaths have occurred during a period when drug and alcohol services are under intense financial pressure. For example, in England local authorities cut budgets by $18 \%$ in real terms between $2013 / 14$ and $2017 / 18,{ }^{57}$ which contributed to a $11 \%$ reduction in people accessing treatment over the same time period.

\section{Maternal and Child Health}

Maternal mortality in the UK is higher than many countries in Central and Northern Europe (Supplementary Material Figure 3). Within the UK there are significant inequalities patterned according to both ethnicity and deprivation..$^{58}$ Compared to white women, there is a five-fold difference in maternal mortality rates for women from a black ethnic backgrounds, and a two-fold difference for women from an Asian ethnic background. Between the most and least deprived groups, there is a two-fold difference in maternal mortality. Rather than narrowing, these trends have been widening over the last decade. ${ }^{58}$

The UK's high mortality from conditions such as asthma, epilepsy, pneumonia and meningococcal disease in childhood, compared to other European countries, ${ }^{59,60}$ also suggests a problem with paediatric care, with infant mortality lagging behind many other high-income countries (Figure 2). ${ }^{61}$ A recent, extremely detailed comparison with Sweden found that newborns in the United Kingdom had many more problems at birth than their counterparts in Sweden, many of which could be traced to their worse socioeconomic status. ${ }^{62}$ Influences on health outcomes start in utero, and there is a clear social gradient in the extent to which children are able to access positive experiences in their early years. ${ }^{24}$ As already mentioned, since 2010 , the UK government has chosen to implement 
prolonged austerity policies, including reductions in entitlements to welfare provision, with measures that have impacted particularly on the most vulnerable. ${ }^{63}$ Concerns have been expressed about the substantial increase in suicide rates among adolescents in England and Wales since 2010. ${ }^{64}$ Child poverty in the UK is currently around $30 \%$, and children are more likely to live in low-income households. ${ }^{65}$ This is predicted to rise over the next few years, and children in single-parent families, with 3 or more siblings, in households where no-one is in work, and in rented or social housing are known to be at particular risk of poverty. ${ }^{66}$ latest year available)

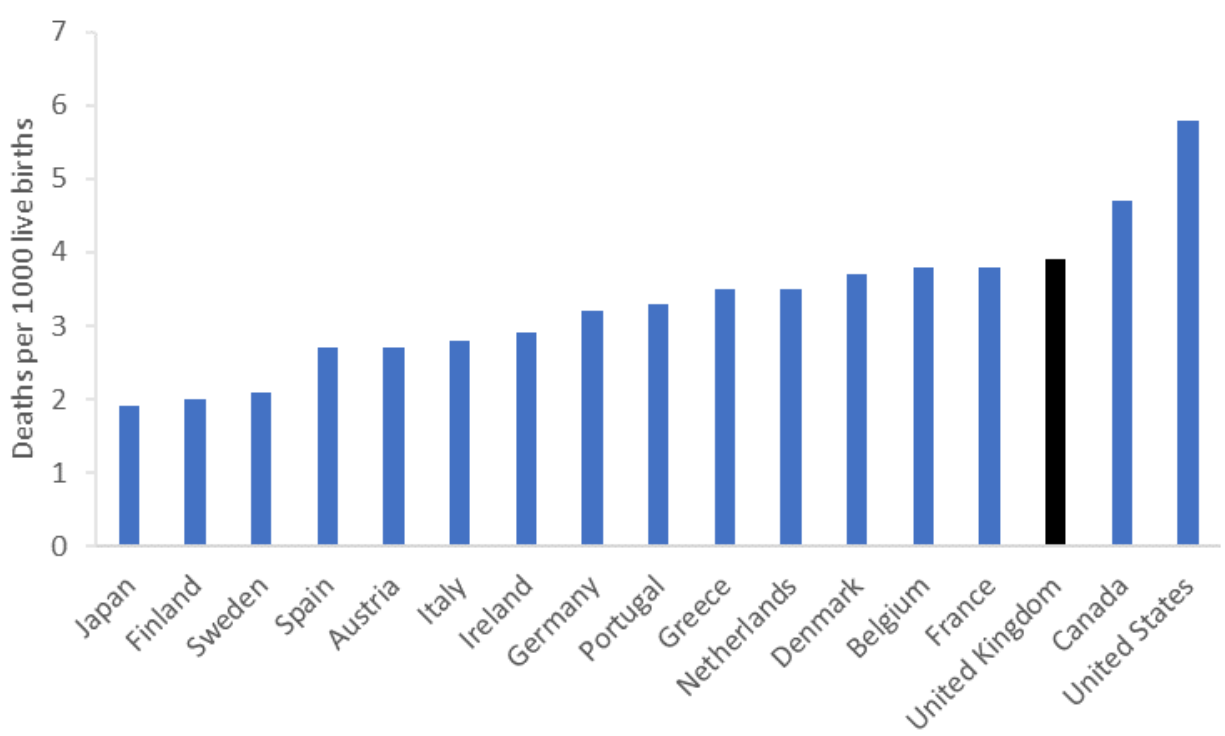

Source: Organisation for Economic Co-operation and Development (OECD) ${ }^{21}$ 
Oral diseases (dental decay, periodontal (gum) diseases and oral cancers) are highly prevalent chronic conditions that have a significant impact on quality of life and are costly to health care systems. The Global Burden of Disease study has highlighted that dental decay in adults is the most prevalent chronic health condition globally - overall it is estimated that 3.5 billion people are affected by dental diseases ${ }^{67}$ A recent analysis shows that the treatment of dental diseases amongst EU countries costs in excess of $€ 90$ billion per year, the third most expensive condition behind diabetes (€119 billion), and cardiovascular diseases (€111 billion). ${ }^{68}$ In recent decades there has been a dramatic change in oral diseases in the UK population. When the NHS was first created the state of oral health in the UK was appalling with the complete removal of all teeth (edentulism) a relatively common occurrence for even young adults, often taking place before marriage. Now less than $5 \%$ of adults in the UK have no natural teeth and overall oral health in the child and adult population has improved greatly. ${ }^{69}$ The retention of more natural teeth is a positive change but as individuals age and become more frail, complex and costly dental treatment is often required. Stark socioeconomic and geographical inequalities in oral health exists. Steep and persistent social gradients are found for oral conditions in both children and adults and oral health is worse in Northern Ireland and Scotland, compared to Wales and England. ${ }^{70}$ Oral diseases are caused by the broader social determinants in society and shared risk factors such as sugars, smoking and alcohol use.

In the UK dental services are organised and funded in a different manner than medical services. The vast majority of the 40,000 dentists in the UK work in primary care providing general dental services to the population. Across the UK different payment systems exist but in all countries co-payments operate where adult patients make a contribution to the costs of their dental treatment. Children and exempt adult groups do not pay for their dental care. Patterns of dental attendance are strongly influenced by socioeconomic status and concerns over the costs of treatment are a major barrier to accessing dental services. ${ }^{71}$

\section{Multimorbidity}


Older people are, individually, more likely to be healthy than in the past. However, the absolute numbers with ill health are increasing. Many will remain healthy by virtue of being treated for hypertension or diabetes thus averting their sequelae. Others, while not in perfect health, experience considerable alleviation of their symptoms. The corollary of this and of earlier detection of chronic diseases and their risk factors is that ever more people experience multimorbidity, requiring some health care, even if only reviews in primary care every few months, for multiple disorders. ${ }^{38}$ Research in the UK estimates that around $23 \%$ of the population meet current criteria for multimorbidity, increasing with age, and attention to early diagnosis, so that the figure is around two-thirds in those over 65 , with nearly half having three or more conditions. ${ }^{38}$ There have been a number of attempts to classify commonly occurring clusters of conditions, and some diseases frequently co-exist, sharing common aetiologies, but there is also much heterogeneity, and illnesses can also be completely unrelated. Chronic physical conditions often co-exist with mental health disorders (particularly dementia), with evidence that the relationship is bi-directional. ${ }^{72}$ There is a clear association between multimorbidity and socioeconomic deprivation, and people living in deprived areas are likely to develop multimorbidity $10-15$ years earlier than those living in more affluent areas. ${ }^{38}$

This has profound implications for how health care is delivered. It demands a holistic approach, often delivered by multidisciplinary teams. The model of primary care, with its generalist approach, has found it easier to respond to this challenge than have some other countries, but the disadvantage, in a country that has somewhat fewer medical specialists than many others (despite growth in specialist posts in recent years), is that it may be difficult to obtain specialist expertise when needed. Unfortunately, the accessibility of primary care is now being threatened, with insufficient historical investment in these services. To compound the problem, chronic staffing shortages coupled with administrative overload add to falling morale and cause physical and practitioners and community nurses. 
The Changing Health Needs of the Population

336 Some changes in future health profiles can be predicted with relative certainty, such as the ageing of

337 the population and, to some extent, a relative fall in those aged $18-65$, albeit with caveats about

338 future migration. ${ }^{73}$ Forecasting with some confidence is possible when the association between risks

339 and disease are known and have long time periods, such as with smoking. It is more difficult when

340 lags between exposure and outcome are short, as with many of the consequences of hazardous

341 drinking, and where public policies can have a major impact in the short term.

342 Although the UK does not have an especially high proportion of older people relative to other highincome countries, with the share of those over 65 and over 80 falling from $4^{\text {th }}$ to $12^{\text {th }}$ between 1995 and 2016 in one comparison of 17 countries (Figure 3), it will eventually face similar challenges to other countries. While ageing per se does not necessarily impact on health care utilisation, if ageing is associated with increased chronic illness and higher rates of multiple long-term conditions, this does add pressure to constrained NHS resources by increasing healthcare utlisation. ${ }^{74}$ 


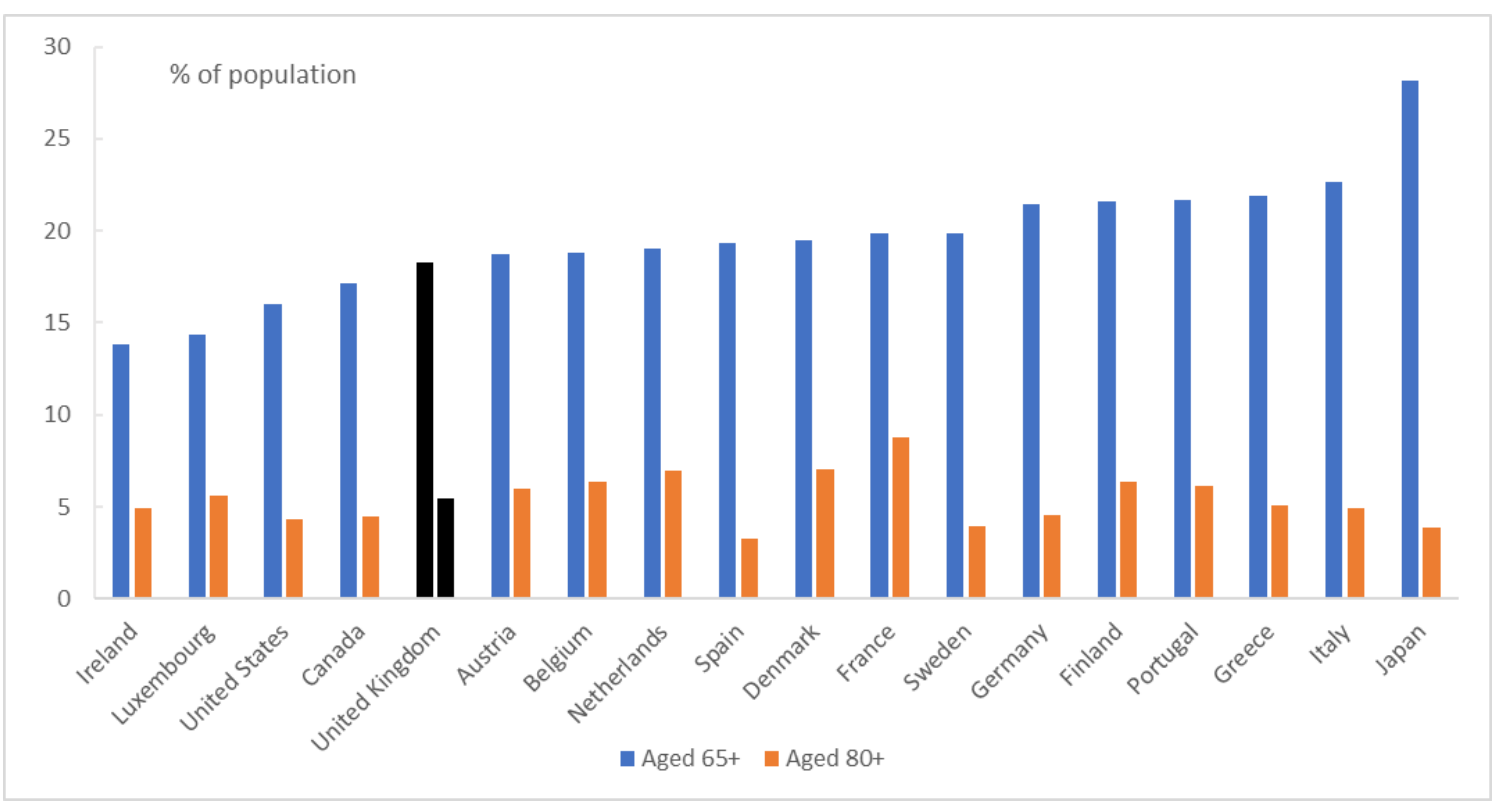

Source: Organisation for Economic Co-operation and Development (OECD) ${ }^{75}$

There is considerable variation within the UK, with the largest share of older and very old people in the South East of England and the smallest in the North East of England (Figure 4). There is also a sizable discrepancy in the age distribution of different ethnic groups (Supplementary Material Figure 4). Both the geographical and ethnic spread of the older population matters, as it leads to specific pressure points on NHS access, as well as contributing to the unequal concentration of ill health within the UK. As ethnicity is not recorded on death certificates in the UK, it is not possible to routinely report on life expectancy stratified by ethnicity. However, a number of recent studies which have used various techniques to try to estimate life expectancy by ethnicity show significant discrepancies between groups which vary by region. ${ }^{76-78}$

Figure 4: Percentage of population aged $65+$ and $85+(2019)$ 


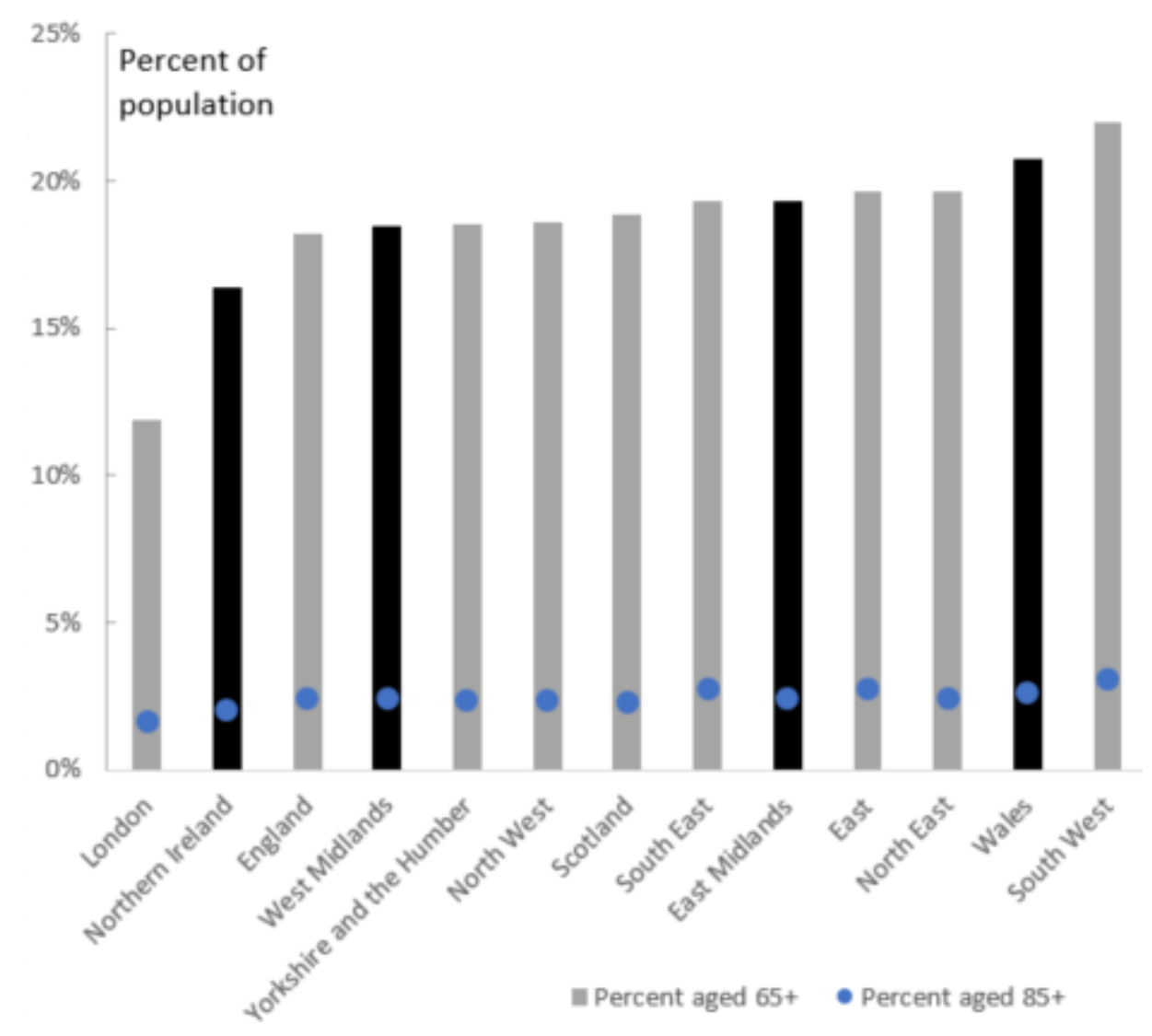

Source: Office for National Statistics (ONS) ${ }^{79}$

The participation of women in the labour market is at an all-time high, ${ }^{80}$ but the threat of future reductions in the proportion of the population in employment will exert further pressure on this group, from whom health and care professionals are drawn. However, caution is needed. The widely-used measure, the old age dependency ratio, has been used in sometimes apocalyptic predictions, typically to argue for the unsustainability of the welfare state. Yet it assumes an 
economically (and socially) inactive stage of life beyond 65 years of age that is no longer the case. The raising of the retirement age, in the United Kingdom and many other countries, has changed such calculations considerably, even before taking account of how older people can be very actively engaged in work and in informal care of spouses, parents, adult children and grandchildren, sometimes with competing demands..$^{81,82}$ There are, however, many uncertainties about the future composition of the UK population, and while it is important not to be alarmist, the experience of Japan, ${ }^{83}$ a country that has experienced very little immigration, albeit for different reasons, is a concern as the young are attracted to major centres for their early working careers, while older people remain in rural or coastal regions, creating a skill gap for care.

In this context, the UK government's stated goal to reduce migration from the "hundreds of thousands" to the "tens of thousands" is a clear cause for concern. The NHS has a long history of relying on foreign recruitment in response to workforce shortfalls. For example, in light of ongoing uncertainty about future EU citizen arrangements, there has been a $90 \%$ reduction in nurses from other EU Member States joining the UK's register in $2017 / 18$ as compared to $2016 / 17 .{ }^{84}$ Growing numbers of medical posts remain unfilled, with the government refusing visas to non-EU doctors with job offers, and even those training in this country. ${ }^{85}$ The social care sector is also heavily dependent on foreign recruitment, yet senior care workers are currently not on the government's 'shortage occupation list' ${ }^{86}$ females 


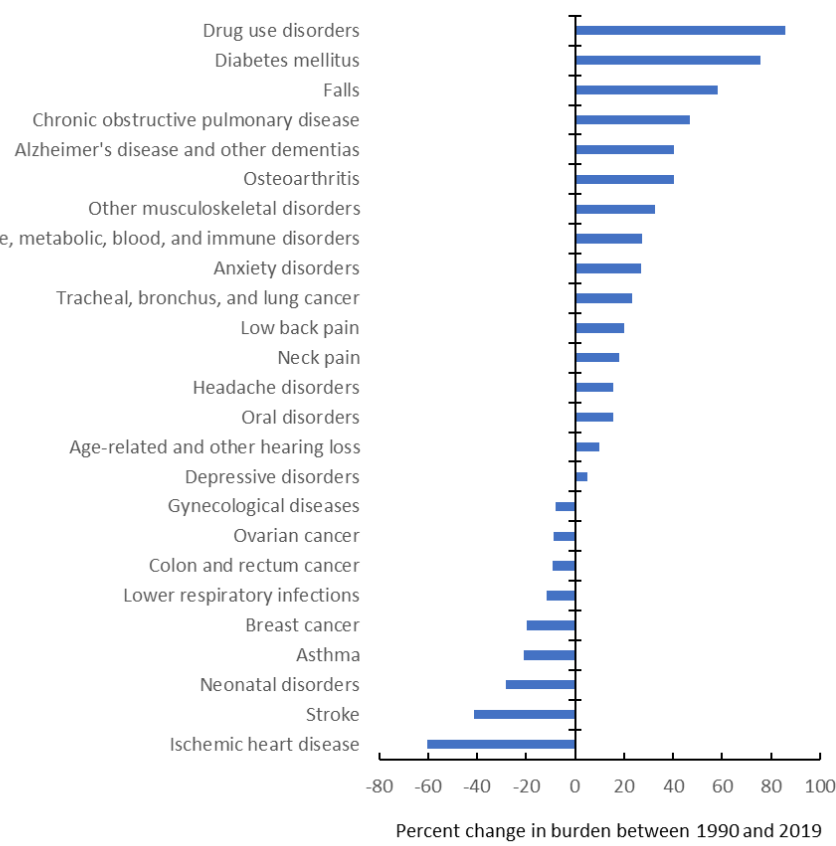

398

399

Source: Global Burden of Disease ${ }^{87}$

400

401 Figure 5b: Percentage change in burden due to the top 25 causes of DALYs in UK, 1990 to 2019,

402

males

Cirrhosis and other chronic liver diseases

Drug use disorders

Diabetes mellitus

Alzheimer's disease and other dementias

Alcohol use disorders

Esophageal cancer

Osteoarthritis

Falls

ther musculoskeletal disorders

Endocrine, metabolic, blood, and immune disorders

Prostate cancer

Age-related and other hearing loss

Headache disorders

Neck pain

Low back pain

Chronic obstructive pulmonary disease

Depressive disorders

Colon and rectum cancer

Lower respiratory infections

Self-harm

Tracheal, bronchus, and lung cancer

Stroke

Neonatal disorders

Road injuries

Ischemic heart disease

$\begin{array}{llllllllllll}-80 & -60 & -40 & -20 & 0 & 20 & 40 & 60 & 80 & 100 & 120 & 140\end{array}$

Percent change in burden between 1990 and 2019

403

Source: Global Burden of Disease ${ }^{87}$ 
The combination of trends in underlying population health, the application of effective preventive interventions and advances in health care have led to a shift in the predominant share of the burden of ill health worldwide from conditions causing premature mortality to conditions that cause disability. Health systems everywhere must thus adapt to the changing nature of health need. The Global Burden of Disease study captures this in its analysis of DALYs. Figure 5 A and B shows the percentage change in burden attributed to the top 25 causes of DALYs in UK for both genders from 1990 to $2019 .{ }^{87}$ For both genders, there have been a significant increases in disease burden due to drug use disorders. In males, addiction problems have been exacerbated further by increases in disease burden due to alcohol use disorders. Addiction services have struggled to meet this rising demand in a context of ongoing funding cuts over the last decade.$^{88}$ This has had implications for NHS services, as harmful drinking has contributed to the increase in disease burden due to liver cirrhosis. Smoking rates have fallen markedly, reducing the future risk of many smoking-related diseases such as stroke and myocardial infarctions, which have been declining for several decades. Although the benefits of this are yet to be felt, with increases in disease burden due to chronic obstructive pulmonary disease experienced in both males and females. Conversely, rates of obesity at younger ages are increasing, with implications for a range of common disorders such as diabetes and cancer, as well as dementia.

Estimates of the proportion of the population aged 65 and over predict an increase of $17.8 \%$ to $24.6 \%$ between 2015 and $2045 .{ }^{89}$ Assuming no change in age-specific utilisation, this would increase demand for health and, especially, social care. ${ }^{90}$ The changing population structure has already led to an absolute increase in numbers of deaths, as predicted, after many years of decline.${ }^{91} \mathrm{~A}$ major component of health costs is driven by proximity to death, not by chronological age, while many older people are now healthier than their counterparts in previous generations. However, the absolute number of older people with multiple conditions is set to increase substantially over the next few decades, potentially more so as the emphasis on early detection continues. As premature 
mortality reduces, disabling conditions whose prevalence increases sharply with age (such as sensory deficits, mobility problems, cognitive decline and incontinence) will progressively accrue, leading to complex multimorbidity. These trends in common conditions have been brought together with population ageing in a dynamic model. ${ }^{90}$ This predicts that the net effect on the numbers of people with four or more conditions will increase between 2015 and 2035 by $21 \%$ in those aged 65 $74,130 \%$ in those aged $75-84$, and $470 \%$ in those aged 85 and over. The changing nature of demand for health and social care that results is a challenge for any health system and requires an explicit response, even more so with a health care system that is encouraging populations to seek medical care for conditions at earlier and earlier stages, sometimes before they are clinically manifest. Therefore, the concern is less ageing per se, but ageing with multiple preventable conditions leading to poor health and wellbeing.

\section{Reducing Need for Healthcare}

One of the key messages of the Tallinn Charter, ${ }^{9}$ mentioned previously, was that effective prevention could reduce the need for health care, and thus the need for scarce resources. This was also a key message of the Wanless Report, commissioned by the UK Treasury. ${ }^{92} \mathrm{It}$ forecast potential to moderate future NHS expenditure if what it called a "fully engaged" policy could be adopted. This concept, of investing in health improvement to reduce future costs, also features prominently in the NHS Long Term Plan. ${ }^{93}$ An additional consideration is the compelling evidence linking better health to economic growth through higher labour force participation and productivity. ${ }^{94}$ There are many examples of successes in implementing health-promoting policies in Europe. ${ }^{95}$ The countries of the UK have been among the leaders internationally in many of the most effective policies to reduce harms associated with use of hazardous substances, such as tobacco, alcohol and, most recently, junk food. Governments have recognised that the most effective policies are those 
based on price, availability and marketing. Examples include minimum alcohol pricing in Scotland and Wales, above-inflation increases in tobacco taxation, a ban on smoking in public places and point-of-sales displays, sugar tax, and standardised cigarette packaging. However, these face powerful lobbying activities by the corresponding industries, both directly and through several "thinktanks" that they fund. ${ }^{96,97}$ For a brief period, the alcohol and food industries benefitted from creation of so-called "responsibility deals", in which the UK government sought to engage with them in official fora. However, the government's own evaluation found that they typically proposed the least effective measures and opposed those known to be effective. ${ }^{98}$ These responsibility deals did lead to pledges from many companies to reduce salt content in food and contributed to a reduction in overall salt intake in the UK of $11 \%$ between 2006 and $2014 .{ }^{99}$ However, eventually key health advocacy organisations withdrew.

Moving forward, there is a need for more joined-up approaches that bring together different groups working on, for example, tobacco, alcohol or diet, working in close collaboration to secure maximum benefit from shifting population norms on the five healthy living imperatives (not smoking, adhering to alcohol guidelines, a healthy weight, physically active and eating a healthy diet) that influence rates of non-communicable diseases. This will require policies that address these issues specifically, but others that take a concerted approach to the upstream determinants of health, including both the well-recognised social determinants of health, but, even more now, the commercial determinants, ${ }^{100}$ looking at how powerful vested interests are able to subvert health policies. It is also necessary to address the political determinants of health, such as austerity and welfare and immigration regimes, and the environmental determinants, such as in the design of healthpromoting cities.

\section{Addressing the Social Determinants of Health}

Although successive governments have adopted effective public health policies, these have struggled in the face of wider societal problems. Consequently, despite noted successes in areas 
such as tobacco control, the UK ranked only $12^{\text {th }}$ overall in an assessment of public health policies across the European Region of the World Health Organization. ${ }^{101}$ Looking ahead, there is clearly a need to address the underlying social determinants of health, or the conditions in which people are born, grow, live, work and age ${ }^{24}$ with policies that address precariousness of employment, income, housing and food security. ${ }^{102}$ The UK has high rates of child poverty, lax building standards and underinvestment in social housing, contributing to many people living in sub-standard accommodation and, since 2010, a marked rise in food insecurity. ${ }^{32}$ Other social problems relate to the employment market: although introduction of a minimum wage was associated with a demonstrable improvement in mental health, ${ }^{103}$ and official unemployment rates are low, there are growing numbers of people who remain below the minimum wage, which is illegal but largely unenforced, ${ }^{104}$ or who face severe uncertainty about income and employment in what is termed the "gig" economy, characterised by piece-work and limited employment rights. Against this background of the erosion of wider welfare policies and falling public expenditure in other areas of welfare, the NHS is increasingly left as the one remaining pillar of the UK welfare state.

Health care is an important route through which health improvements can be channelled, but other sectors remain important in addressing health promotion and inequalities. There is compelling evidence, in many areas, that health promoting policies work, especially those that involve all relevant sectors, enshrined in the concept of "Health in All Policies". Wales is pioneering this approach through The Wellbeing of Future Generations Act 2015 and the Public Health Act, $2017 \cdot{ }^{105,106}$ As a major employer, this is an area where the NHS could play a major role, although this would require a substantial culture change in an organisation that is more often associated with high levels of work-related stress and burnout. Health-promoting policies do have the potential not only to alleviate suffering but also to reduce further the demand on the NHS if there is the political will to implement them. 
507 The initial version of this paper argued that the NHS must prepare for the unexpected, ensuring that

508 it was resilient in the face of potential threats, including a pandemic, ${ }^{107}$ especially given the threat posed by the loss of links with European agencies such as the European Centre for Disease Control (ECDC) and the European Monitoring Centre for Drugs and Drug Addiction. ${ }^{108,109}$ The COVID-19 pandemic has, tragically, revealed that the UK was less prepared than it could have been.

As of November 2020 it was one of the worst affected countries in the world, whether deaths were measured as those attributed directly to COVID-19 or by excess all-cause mortality, the preferred measure for international comparisons. There will be many lessons to learn from the response: confused messaging by ministers; outsourcing of essential functions to companies lacking expertise; fragmentation of the NHS, public health, and social care systems; understanding the factors which underpin elevated mortality rates experienced by black and minority ethnic groups; relationships between central and local government, as well as with devolved nations; serious failures in procurement of essential items, from ventilators to test kits, personal protective equipment; and entire new, but largely unused, hospital facilities. ${ }^{110}$ It should also be recognised how many aspects of the response by those working in the NHS was exceptional, repurposing existing hospital facilities, rapidly expanding access to teleconsultations, reallocating staff, sharing knowledge about the emerging clinical characteristics of this disease, and implementing a world leading clinical trial programme. ${ }^{111}$ Impacts in parts of the social care sector (especially in care homes), have been devastating, and responses by staff similarly exceptional, again with many lessons to be learned. ${ }^{112}$

The UK's response has, however, come at an enormous cost, both financially and in terms of the

527 long-term consequences for health. These can be considered under five headings: the long-term consequences of the infection on the body, delays in care as a consequence of suspension of certain

529 NHS services, the health effects of the lockdown, the impact on NHS staff, and the long-term economic impact. In the first category, it is becoming clear that many of those who survive COVID-19 
are experiencing persisting health problems, many apparently associated with the action of the virus on vascular endothelium and the associated immune response and hypercoagulability. ${ }^{113}$ In this respect, some have questioned whether it will come to be compared with polio, which also left a long-lasting legacy of ill health. In the second category, there was a large reduction in primary care attendances, ${ }^{114}$ storing up considerable unmet need for the future, and routine surgery has been suspended, leaving a massive backlog to be treated in what was an already struggling system. Delayed diagnosis and treatment of early stage cancer has been estimated to lead to over 6,000 additional deaths in a year. ${ }^{115}$ Estimates suggest that 3,800 early cancers that would have been picked up on screening have been missed. ${ }^{116}$ In the third category, prolonged isolation, coupled with cessation of specialist services, is likely to contribute to an increased burden of mental illness, while closure of schools is likely to contribute to mental illness in children and young people. ${ }^{7}$ The fourth category includes the effects of psychological trauma on NHS and social care staff, including responses more usually seen in survivors of armed conflict. ${ }^{117}$ Fifth, the pandemic is expected to lead to a long-term reduction in economic growth, ${ }^{118}$ that could see many of the health problems associated with austerity in the period after 2010 return. ${ }^{102}$ To add to the problems, the ability of the NHS to respond may be complicated by the need for new ways of working, including greater use of personal protective equipment, social distancing, and remote consultations.

There are also other threats ahead, some more certain than others. One is antimicrobial resistance, an area where the UK has shown global leadership. ${ }^{119}$ Another is the consequences of a generation transitioning into retirement in a much more precarious state than their parents because of closure or reduction of pension schemes and less home ownership, who may struggle to come to terms with their straitened circumstances. ${ }^{95} \mathrm{~A}$ third is climate change, with evidence that the climate is changing even faster than predicted, potentially nearing a tipping point of runaway global warming.

554 The COVID-19 pandemic has ushered in a temporary period of reduced carbon emissions,

555 government actions and economic incentives post pandemic will determine whether carbon emissions continue on the same path. ${ }^{120}$ 
In summary, the future is uncertain. Some of the uncertainties can be anticipated, to some extent. For others, it is more difficult. The lesson from the COVID-19 pandemic is that the NHS must both anticipate predictable developments and build in sufficient resilience for the unexpected and work with other sectors to develop holistic solutions.

The UK leaving the European Union will have adverse consequences for health. ${ }^{121}$ However, the UK has failed to engage effectively with the process of negotiating a future trade deal with the EU. ${ }^{122}$ As of November 2020, the prospect of anything more than a minimal agreement in place in early 2020 seems remote. This makes it very difficult to have any clear understanding of what the future situation might be. There will be many direct impacts on the health system, including those on the workforce and employment law, access to medicines and medical devices, funding for research and sharing of vital public health information about communicable diseases. "No deal' planning has been focussed on developing alternative systems to mitigate risks but these have suffered greatly during the COVID-19 pandemic. Beyond the immediate problems, the health of the UK population is affected by many other aspects of public policy. Food quality and safety, agriculture, landmanagement and environmental regulations are just a few of the areas of concern currently addressed by EU legislation which have significant implications for human health. ${ }^{123}$ Of particular concern to health and health services will be the nature of any future international trade agreements. Issues around Intellectual Property Rights, Technical Barriers to Trade and Investor Protection need to be thought through carefully, ${ }^{124}$ and protections for health and healthcare put in place. It is vitally important that in the new trade agreements health is not subverted by commercial interests for economic gain. ${ }^{125}$ Overall economic performance following departure from the

579 European Union will also be very important, with implications not just for the available funds to

580 spend on health, but for the wellbeing of the UK population and the consequent demand for 581 healthcare. 


\section{Conclusion}

583 This paper has reviewed the current health of the UK population, changing health needs and

584 considered what future challenges lie ahead. From this we can draw several conclusions.

585 First, despite significant improvements in life expectancy, many physical and mental health

586 outcomes are suboptimal relative to other high income countries. Driving this sub-optimality is that,

587 across all ages, but especially in childhood and old age, the population has high levels of preventable

588 ill health which are unfairly distributed across society. As the UK has experienced a relatively high

589 excess mortality rate attributable to COVID-19, the gap in life expectancy between the UK and other developed countries is likely to grow.

591

Second, in the future there will be relatively fewer people in the working population, especially if current policies on migration continue, and a sharp rise in people with complex multimorbidity. This creates a mismatch between needs and capacity to address those needs, both through workforce availability and securing the economic basis for sustainable funding. To address these issues there needs to be an increased focus on prevention and health promotion that takes a multisectoral approach to the social, political and commercial causes of poor health. The crucial role the NHS can play by setting an example as a healthy employer, reducing risk factors for chronic diseases, promoting healthy ageing, enhancing confidence and promoting social engagement, should be addressed explicitly. However, the NHS is increasingly operating in an environment where other sectors (especially social care), instead of being maintained as supportive, are being eroded in terms of expenditure and general infrastructure.

Finally, there are many immediate threats which will affect the health of the population and service provision. Crucially the UK will need to develop strategies to mitigate against the wider and longterm consequences for health of the COVID-19 pandemic. Alongside this, the UK's impending departure from the EU, growing antimicrobial resistance and increasing climate change are all major challenges with significant consequences for the NHS. Other unforeseen risks such as economic 
downturn or even conflict would impact the NHS but are practically difficult to plan for. Instead the focus should be on building a resilient and preventative healthcare service, so that the NHS is better prepared for any future challenges.

\section{References}

1 Wolfe I, Mckee M. European Child Health Services And Systems: Lessons Without Borders. UK: Open University Press, 2013.

2 McKee M, Healy J. The role of the hospital in a changing environment. Bull World Health Organ 2000; 78: 803-10.

3 Kleinman ER, Harper PR, Gallagher JE. Trends in NHS primary dental care for older people in England: implications for the future. Gerodontology 2009; 26: 193-201.

4 Dubois C-A, Mckee M. Cross-national comparisons of human resources for health - what can we learn? Health Econ Policy Law 2006; 1: 59-78.

5 Nolte E, McKee M. Caring for People with Chronic Conditions: A Health System Perspective. McGraw-Hill Education (UK), 2008.

6 Healthcare Quality Improvement Partnership. The National Clinical Audit Programme. https://www.hqip.org.uk/a-z-of-nca/\#.XSxOXuhKhPZ (accessed November 17, 2020).

7 Douglas M, Katikireddi SV, Taulbut M, McKee M, McCartney G. Mitigating the wider health effects of covid-19 pandemic response. BMJ 2020; 369. DOI:10.1136/bmj.m1557.

8 World Health Organization. The World Health Report 2000: health systems: improving performance. Geneva: WHO, 2000. https://www.who.int/whr/2000/en/ (accessed November 17, 2020).

9 World Health Organisation. The Tallinn Charter: Health Systems for Health and Wealth. 2008. http://www.euro.who.int/en/media-centre/events/events/2008/06/who-europeanministerial-conference-on-health-systems/documentation/conference-documents/thetallinn-charter-health-systems-for-health-and-wealth (accessed November 17, 2020).

10 McKee M, Suhrcke M, Nolte E, et al. Health systems, health, and wealth: a European perspective. Lancet 2009; 373: 349-51.

11 Public Health England. A review of recent trends in mortality in England. 2019. https://assets.publishing.service.gov.uk/government/uploads/system/uploads/attachment_d 
ata/file/786515/Recent trends in mortality in England.pdf (accessed November 17, 2020).

12 Leon DA, Jdanov DA, Shkolnikov VM. Trends in life expectancy and age-specific mortality in England and Wales, 1970-2016, in comparison with a set of 22 high-income countries: an analysis of vital statistics data. Lancet Public Health 2019; 4: e575-82.

13 Office for National Statistics. Child and infant mortality in England and Wales: 2017. 2019. https://www.ons.gov.uk/peoplepopulationandcommunity/birthsdeathsandmarriages/deaths/ bulletins/childhoodinfantandperinatalmortalityinenglandandwales/2017 (accessed November 17, 2020).

14 Taylor-Robinson D, Lai ETC, Wickham S, et al. Assessing the impact of rising child poverty on the unprecedented rise in infant mortality in England, 2000-2017: time trend analysis. BMJ Open 2019; 9: e029424.

15 Loopstra R, McKee M, Katikireddi SV, Taylor-Robinson D, Barr B, Stuckler D. Austerity and old-age mortality in England: a longitudinal cross-local area analysis, 2007-2013. J R Soc Med 2016; 109: 109-16.

16Hiam L, Harrison D, McKee M, Dorling D. Why is life expectancy in England and Wales 'stalling'? J Epidemiol Community Health 2018; 72: 404-8.

17 Hiam L, Dorling D, Harrison D, McKee M. What caused the spike in mortality in England and Wales in January 2015? J R Soc Med 2017; 110: 131-7.

18 Marshall L, Finch D, Cairncross L, Bibby J. Mortality and life expectancy trends in the UK: stalling progress. 2019. https://www.health.org.uk/publications/reports/mortality-andlife-expectancy-trends-in-the-uk (accessed November 17, 2020).

19 Roberts CM, Levi M, McKee M, Schilling R, Lim WS, Grocott MP. COVID-19: a complex multi-system disorder. Br J Anaesth 2020.

20 Richards M, Anderson M, Carter P, Ebert BL, Mossialos E. The impact of the COVID-19 pandemic on cancer care. Nat Cancer 2020; : 565-7.

21 OECD. Health Statistics. http://www.oecd.org/els/health-systems/health-data.htm (accessed November 17, 2020).

22 Hiam L, Dorling D, Harrison D, McKee M. Why has mortality in England and Wales been increasing? An iterative demographic analysis. J R Soc Med 2017; 110: 153-62.

23 Newton JN, Briggs ADM, Murray CJL, et al. Changes in health in England, with analysis by English regions and areas of deprivation, 1990-2013: a systematic analysis for the Global Burden of Disease Study 2013. Lancet 2015; 386: 2257-74.

24 Marmot M. Fair Society Healthy Lives (The Marmot Review). 2010. http://www.instituteofhealthequity.org/resources-reports/fair-society-healthy-lives-themarmot-review (accessed November 17, 2020). 
25 Wohland P, Rees P, Nazroo J, Jagger C. Inequalities in healthy life expectancy between ethnic groups in England and Wales in 2001. Ethn Health 2015; 20: 341-53.

26 Office for National Statistics. Coronavirus (COVID-19) related deaths by ethnic group, England and Wales. 2020. https:/www.ons.gov.uk/peoplepopulationandcommunity/birthsdeathsandmarriages/deaths/ articles/coronaviruscovid19relateddeathsbyethnicgroupenglandandwales/2march2020to15 may2020 (accessed November 17, 2020).

27 Devakumar D, Selvarajah S, Shannon G, et al. Racism, the public health crisis we can no longer ignore. Lancet 2020; 395: e112-3.

28 Godlee F. Racism: the other pandemic. BMJ 2020; 369.

29 Whitehead M, Dahlgren G. What can be done about inequalities in health? Lancet 1991; 338: $1059-63$.

30 Cummins I. The Impact of Austerity on Mental Health Service Provision: A UK Perspective. Int J Environ Res Public Health 2018; 15.

31 Reeves A, Clair A, McKee M, Stuckler D. Reductions in the United Kingdom's Government Housing Benefit and Symptoms of Depression in Low-Income Households. Am J Epidemiol 2016; 184: 421-9.

32 Loopstra R, Reeves A, Taylor-Robinson D, Barr B, McKee M, Stuckler D. Austerity, sanctions, and the rise of food banks in the UK. BMJ 2015; 350: h1775.

33 OECD, World Health Organisation. Poverty and Health: DAC Guidelines and Reference Series. Paris: OECD, 2003. https://www.who.int/tobacco/research/economics/publications/oecd_dac_pov_health.pdf (accessed November 17, 2020).

34 UK Parliament. Mental health statistics for England: prevalence, services and funding Commons Library briefing. https://researchbriefings.parliament.uk/ResearchBriefing/Summary/SN06988 (accessed November 17, 2020).

35 The Academy of Medical Sciences. Survey results: Understanding people's concerns about the mental health impacts of the COVID-19 pandemic. 2020. https://acmedsci.ac.uk/file-download/99436893 (accessed November 17, 2020).

36Holmes EA, O'Connor RC, Perry VH, et al. Multidisciplinary research priorities for the COVID-19 pandemic: a call for action for mental health science. Lancet Psychiatry 2020; 7: $547-60$.

37 United Nations. COVID-19 and the Need for Action on Mental Health. 2020. https://www.un.org/sites/un2.un.org/files/un_policy_briefcovid_and_mental_health_final.pdf (accessed November 17, 2020).

38 Barnett K, Mercer SW, Norbury M, Watt G, Wyke S, Guthrie B. Epidemiology of multimorbidity and implications for health care, research, and medical education: a crosssectional study. Lancet 2012; 380: 37-43. 
39 Health and Safety Executive. Working days lost in Great Britain. http://www.hse.gov.uk/statistics/dayslost.htm (accessed November 17, 2020).

40 Farmer P, Stevenson D. Thriving at Work: The Stevenson/ Farmer review of mental health and employers. 2017. https://www.gov.uk/government/publications/thriving-at-work-areview-of-mental-health-and-employers (accessed November 17, 2020).

41 Matthews FE, Arthur A, Barnes LE, et al. A two-decade comparison of prevalence of dementia in individuals aged 65 years and older from three geographical areas of England: results of the Cognitive Function and Ageing Study I and II. Lancet 2013; 382: 1405-12.

42 Prince M, Knapp M, Guerchet M, et al. Dementia UK. Second Edition. Alzhiermer's Society. 2014.

https://www.alzheimers.org.uk/sites/default/files/migrate/downloads/dementia_uk_update. pdf (accessed November 17, 2020).

43 Age UK. Hidden in plain sight: The unmet mental health needs of older people. 2016. https://www.ageuk.org.uk/documents/en-gb/for-professionals/policy/health-andwellbeing/hidden_in_plain_sight_older_peoples_mental_health.pdf?dtrk=true (accessed November 17, 2020).

44 Bryant $\mathrm{C}$, Jackson $\mathrm{H}$, Ames D. The prevalence of anxiety in older adults: methodological issues and a review of the literature. J Affect Disord 2008; 109: 233-50.

45 Burns A. Better access to mental health services for older people. NHS England, 2015. https://www.england.nhs.uk/blog/mh-better-access/ (accessed November 17, 2020).

46 Royal College of Psychiatrists. Suffering in silence: age inequality in older people's mental health care. 2018. https://www.rcpsych.ac.uk/improving-care/campaigning-forbetter-mental-health-policy/college-reports/2018-college-reports/cr221 (accessed November 17, 2020).

47 Gunnell D, Kidger J, Elvidge H. Adolescent mental health in crisis. BMJ 2018; 361: $\mathrm{k} 2608$.

48 NHS Digital. Mental Health of Children and Young People in England, 2017. 2018. https://digital.nhs.uk/data-and-information/publications/statistical/mental-health-ofchildren-and-young-people-in-england/2017/2017 (accessed November 17, 2020).

49 Universities UK. Minding our future: starting a conversation about the support of student mental health. 2018. https://www.universitiesuk.ac.uk/policy-andanalysis/reports/Pages/minding-our-future-starting-a-conversation-support-student-mentalhealth.aspx (accessed November 17, 2020).

50 Morgan C, Webb RT, Carr MJ, et al. Incidence, clinical management, and mortality risk following self harm among children and adolescents: cohort study in primary care. $B M J$ 2017; 359: j4351.

51 Kessler RC, Berglund P, Demler O, Jin R, Merikangas KR, Walters EE. Lifetime prevalence and age-of-onset distributions of DSM-IV disorders in the National Comorbidity Survey Replication. Arch Gen Psychiatry 2005; 62: 593-602. 
52 Office for National Statistics. Alcohol-specific deaths in the UK: registered in 2017. 2018. https://www.ons.gov.uk/peoplepopulationandcommunity/healthandsocialcare/causesofdeat $\mathrm{h} /$ bulletins/alcoholrelateddeathsintheunitedkingdom/registeredin2017\#comparisonsbetween-the-four-countries-of-the-uk (accessed November 17, 2020).

53 Office for National Statistics. Deaths related to drug poisoning in England and Wales: 2017 registrations. 2018. https://www.ons.gov.uk/peoplepopulationandcommunity/birthsdeathsandmarriages/deaths/ bulletins/deathsrelatedtodrugpoisoninginenglandandwales/2017registrations\#drugpoisoning-deaths-in-2017-remained-stable (accessed November 17, 2020).

54 National Records of Scotland. Drug-related deaths in Scotland in 2018. 2019. https://www.nrscotland.gov.uk/files/statistics/drug-related-deaths/2018/drug-relateddeaths-18-pub.pdf (accessed November 17, 2020).

55 Barnsdale L, Guonari X, Graham L. The National Drug Related Deaths Database (Scotland) Report Analysis of Deaths occurring in 2015 and 2016. ISD Scotland. 2018. https://www.isdscotland.org/Health-Topics/Drugs-and-Alcohol-Misuse/Publications/201806-12/2018-06-12-NDRDD-Report.pdf (accessed November 17, 2020).

56 Office for National Statistics. Alcohol-specific deaths in the UK: liver diseases and the impact of deprivation. 2018.

https://www.ons.gov.uk/peoplepopulationandcommunity/healthandsocialcare/causesofdeat $\mathrm{h} /$ datasets/alcoholspecificdeathsintheunitedkingdomsupplementarydatatables (accessed November 17, 2020).

57 Rhodes D. Drug and alcohol services cut by $£ 162 \mathrm{~m}$ as deaths increase. BBC News. Published online 11 May. 2018. https://www.bbc.com/news/uk-england-44039996 (accessed November 17, 2020).

58 Knight M, Bunch K, Kenyon S, Tuffnell D, Kurinczuk JJ. A national population-based cohort study to investigate inequalities in maternal mortality in the United Kingdom, 200917. Paediatr Perinat Epidemiol 2020; 34: 392-8.

59 Shah R, Hagell A, Cheung R. International comparisons of health and wellbeing in adolescence and early adulthood. 2019. https://www.nuffieldtrust.org.uk/files/201902/1550657729_nt-ayph-adolescent-health-report-web.pdf (accessed November 17, 2020).

60 Royal College of Paediatrics and Child Health. Child health in 2030 in England: comparisons with other wealthy countries. 2018. https://www.rcpch.ac.uk/sites/default/files/2018-10/child_health_in_2030_in_england_report_2018-10.pdf (accessed November 17, 2020).

61 Wolfe I, Thompson M, Gill P, et al. Health services for children in western Europe. Lancet 2013; 381: 1224-34.

62 Zylbersztejn A, Gilbert R, Hjern A, Wijlaars L, Hardelid P. Child mortality in England compared with Sweden: a birth cohort study. Lancet 2018; 391: 2008-18.

63 Karanikolos M, Mladovsky P, Cylus J, et al. Financial crisis, austerity, and health in Europe. Lancet 2013; 381: 1323-31. 
64 Bould H, Mars B, Moran P, Biddle L, Gunnell D. Rising suicide rates among adolescents in England and Wales. Lancet 2019; 394: 116-7.

65 UK Government National Statistics. Households below average income: 1994/95 to 2017/18. 2019. https://www.gov.uk/government/statistics/households-below-averageincome-199495-to-201718 (accessed November 17, 2020).

66 Resolution Foundation. The Living Standards Outlook 2019. https://www.resolutionfoundation.org/publications/the-living-standards-outlook2019/ (accessed November 17, 2020).

67 Kassebaum NJ, Smith AGC, Bernabé E, et al. Global, Regional, and National Prevalence, Incidence, and Disability-Adjusted Life Years for Oral Conditions for 195 Countries, 1990-2015: A Systematic Analysis for the Global Burden of Diseases, Injuries, and Risk Factors. J Dent Res 2017; 96: 380-7.

68 Peres MA, Macpherson LMD, Weyant RJ, et al. Oral diseases: a global public health challenge. Lancet 2019; 394: 249-60.

69 Steele JG, Treasure ET, O’Sullivan I, Morris J, Murray JJ. Adult Dental Health Survey 2009: transformations in British oral health 1968-2009. Br Dent J 2012; 213: 523-7.

70 Shen J, Wildman J, Steele J. Measuring and decomposing oral health inequalities in an UK population. Community Dent Oral Epidemiol 2013; 41: 481-9.

71 Watt RG, Steele JG, Treasure ET, White DA, Pitts NB, Murray JJ. Adult Dental Health Survey 2009: implications of findings for clinical practice and oral health policy. Br Dent $J$ 2013; 214: 71-5.

72 The Academy of Medical Sciences. Multimorbidity: a priority for global health research. 2018. https://acmedsci.ac.uk/policy/policy-projects/multimorbidity (accessed November $17,2020)$.

73 Astolfi R, Lorenzoni L, Oderkirk J. A comparative analysis of health forecasting methods. Paris, France: OECD, 2012. https://www.oecd-ilibrary.org/docserver/5k912j389bf0en.pdf? expires $=1574098032 \& \mathrm{id}=\mathrm{id} \&$ accname $=$ guest $\&$ checksum $=5008 \mathrm{~F} 7893831 \mathrm{~B} 7246 \mathrm{D}$ F3827F9410C95E (accessed November 17, 2020).

74 Palladino R, Tayu Lee J, Ashworth M, Triassi M, Millett C. Associations between multimorbidity, healthcare utilisation and health status: evidence from 16 European countries. Age Ageing 2016; 45: 431-5.

75 OECD. Elderly population - OECD Data. http://data.oecd.org/pop/elderly-population.htm (accessed November 17, 2020).

76 Morris M, Woods LM, Rachet B. A novel ecological methodology for constructing ethnicmajority life tables in the absence of individual ethnicity information. $J$ Epidemiol Community Health 2015; 69: 361-7.

77 Gruer L, Cézard G, Clark E, et al. Life expectancy of different ethnic groups using death records linked to population census data for 4.62 million people in Scotland. J Epidemiol Community Health 2016; 70: 1251-4. 
78 Rees PH, Wohland PN, Norman PD. The estimation of mortality for ethnic groups at local scale within the United Kingdom. Soc Sci Med 2009; 69: 1592-607.

79 Office for National Statistics. Population estimates for the UK, England and Wales, Scotland and Northern Ireland: mid-2019. 2020. https://www.ons.gov.uk/peoplepopulationandcommunity/populationandmigration/populati onestimates/bulletins/annualmidyearpopulationestimates/latest (accessed November 17, 2020).

80 UK Parliament. Women and the economy. House of Commons Library, 2019. https://researchbriefings.parliament.uk/ResearchBriefing/Summary/SN06838 (accessed November 17, 2020).

81 Solomi VL, Casiday RE. In sickness and in health: The strains and gains of caring for a chronically ill or disabled spouse. Chronic Illn 2017; 13: 75-87.

82 Pickard L. Substitution between formal and informal care: a 'natural experiment' in social policy in Britain between 1985 and 2000. Ageing Soc 2012; 32: 1147-75.

83 Coulmas F. Population Decline and Ageing in Japan - The Social Consequences. Routledge, 2007.

84 Nursing \& Midwifery Council. Annual reports and accounts 2017-2018. https://www.nmc.org.uk/about-us/reports-and-accounts/annual-reports-and-accounts/ (accessed November 17, 2020).

85 Eversheds Sutherland. Restricted Certificates of Sponsorship: Key Points from Data. 2018. https://www.evershedssutherland.com/global/en/what/articles/index.page?ArticleID=en/Employment and labour _law/Restricted-certificates-of-sponsorship-key-points (accessed November 17, 2020).

86 Patel P. Home Secretary letter to the MAC in response to the shortage occupation lists report. UK Government, 2020 https://www.gov.uk/government/publications/letter-to-themac-on-the-shortage-occupation-lists-report/home-secretary-letter-to-the-mac-in-responseto-the-shortage-occupation-lists-report-accessible-version (accessed November 17, 2020).

87 The Institute for Health Metrics and Evaluation (IHME). GBD Data Visualizations. http://www.healthdata.org/gbd/data-visualizations (accessed November 17, 2020).

88 Drummond C. Cuts to addiction services are a false economy. BMJ 2017; 357. DOI:10.1136/bmj.j2704.

89 Office for National Statistics. Overview of the UK population: March 2017. 2017. https://www.ons.gov.uk/peoplepopulationandcommunity/populationandmigration/populati onestimates/articles/overviewoftheukpopulation/mar2017 (accessed November 17, 2020).

90 Kingston A, Robinson L, Booth H, Knapp M, Jagger C, MODEM project. Projections of multi-morbidity in the older population in England to 2035: estimates from the Population Ageing and Care Simulation (PACSim) model. Age Ageing 2018; 47: 374-80.

91 Gomes B, Higginson IJ. Where people die (1974--2030): past trends, future projections and implications for care. Palliat Med 2008; 22: 33-41. 
92 Wanless D. Securing our future health: taking a long-term view. 2002.

93 NHS England. NHS Long Term Plan. 2019. https://www.england.nhs.uk/long-term-plan/ (accessed November 17, 2020).

94 Suhrcke M, McKee M, Arce RS, Tsolova S, Mortensen J. Investment in health could be good for Europe's economies. BMJ 2006; 333: 1017-9.

95 Mackenbach JP, Karanikolos M, McKee M. The unequal health of Europeans: successes and failures of policies. Lancet 2013; 381: 1125-34.

96 Williams R, Alexander G, Aspinall R, et al. Gathering momentum for the way ahead: fifth report of the Lancet Standing Commission on Liver Disease in the UK. Lancet 2018; 392: $2398-412$.

97 McCambridge J, Daube M, McKee M. Brussels Declaration: a vehicle for the advancement of tobacco and alcohol industry interests at the science/policy interface? Tob Control 2019; 28: 7-12.

98 Knai C, Petticrew M, Durand MA, Eastmure E, Mays N. Are the Public Health Responsibility Deal alcohol pledges likely to improve public health? An evidence synthesis. Addict Abingdon Engl 2015; 110: 1232-46.

99 Public Health England. Salt Reduction Programme. 2018. https://publichealthengland.exposure.co/salt-reduction-programme (accessed November $17,2020)$.

100 McKee M, Stuckler D. Revisiting the Corporate and Commercial Determinants of Health. Am J Public Health 2018; 108: 1167-70.

101 Mackenbach J. Successes and failures of health policy in Europe. Eur J Public Health $2013 ; 23$.

102 McKee M, Reeves A, Clair A, Stuckler D. Living on the edge: precariousness and why it matters for health. Arch Public Health 2017; 75: 13.

103 Reeves A, McKee M, Mackenbach J, Whitehead M, Stuckler D. Introduction of a National Minimum Wage Reduced Depressive Symptoms in Low-Wage Workers: A Quasi-Natural Experiment in the UK. Health Econ 2017; 26: 639-55.

104 Low Pay Commission. Non-compliance and enforcement of the National Minimum Wage. UK Government. 2019. https://www.gov.uk/government/news/minimum-wageunderpayment-on-the-rise-low-pay-commission-finds (accessed November 17, 2020).

105 World Health Organization. Sustainable development in Wales and other regions in Europe - achieving health and equity for present and future generations. 2017. http://www.euro.who.int/en/publications/abstracts/sustainable-development-in-wales-andother-regions-in-europe-achieving-health-and-equity-for-present-and-future-generations2017 (accessed November 17, 2020). 
106 Welsh Government. Public Health (Wales) Act 2017. 2017. http://www.legislation.gov.uk/anaw/2017/2/contents/enacted (accessed November 17, 2020).

107 Castleden M, McKee M, Murray V, Leonardi G. Resilience thinking in health protection. J Public Health Oxf Engl 2011; 33: 369-77.

108 Fahy N, Hervey T, Greer S, et al. How will Brexit affect health services in the UK? An updated evaluation. Lancet 2019; 393: 949-58.

109 Roman-Urrestarazu A, Yang J, Robertson R, et al. Brexit threatens the UK's ability to tackle illicit drugs and organised crime: what needs to happen now? Health Policy 2019 123(6): 521-525

110 Horton R. The COVID-19 Catastrophe: What's Gone Wrong and How to Stop It Happening Again, 1st edition. Cambridge: Polity, 2020.

111 Wilkinson E. RECOVERY trial: the UK covid-19 study resetting expectations for clinical trials. $B M J$ 2020; 369: m1626.

112 Rajan S, Comas-Herrera A, Mckee M. Did the UK Government Really Throw a Protective Ring Around Care Homes in the COVID-19 Pandemic? J Long-Term Care 2020; : 185-195.

113 Roberts C, Levi M, Schilling R, Lim W, Grocott M, McKee M. Covid-19: a complex multisystem clinical syndrome. The BMJ. 2020; published online May 1. https://blogs.bmj.com/bmj/2020/05/01/covid-19-a-complex-multisystem-clinicalsyndrome/ (accessed November 17, 2020).

114 Mansfield KE, Mathur R, Tazare J, et al. COVID-19 collateral: Indirect acute effects of the pandemic on physical and mental health in the UK. medRxiv 2020; : 2020.10.29.20222174.

115 Lai AG, Pasea L, Banerjee A, et al. Estimating excess mortality in people with cancer and multimorbidity in the COVID-19 emergency. medRxiv 2020; : 2020.05.27.20083287.

116 Campbell D. Millions in UK miss cancer screenings, tests and treatments due to Covid19. The Guardian. 2020. https://www.theguardian.com/society/2020/jun/01/millions-in-ukmiss-cancer-screenings-tests-and-treatments-due-to-covid-19 (accessed November 17, 2020).

117 Greenberg N, Docherty M, Gnanapragasam S, Wessely S. Managing mental health challenges faced by healthcare workers during covid-19 pandemic. BMJ 2020; 368.

118 McKee M, Stuckler D. If the world fails to protect the economy, COVID-19 will damage health not just now but also in the future. Nat Med 2020; : 1-3.

119 Keown OP, Warburton W, Davies SC, Darzi A. Antimicrobial resistance: addressing the global threat through greater awareness and transformative action. Health Aff Proj Hope 2014; 33: 1620-6. 
120 Le Quéré C, Jackson RB, Jones MW, et al. Temporary reduction in daily global CO 2 emissions during the COVID-19 forced confinement. Nat Clim Change 2020; 10: 647-53.

121 Fahy N, Hervey T, Greer S, et al. How will Brexit affect health and health services in the UK? Evaluating three possible scenarios. Lancet 2017; 390: 2110-8.

122 Fahy N, Hervey T, Dayan M, et al. Assessing the potential impact on health of the UK's future relationship agreement with the EU: analysis of the negotiating positions. Health Econ Policy Law 2020; : 1-18.

123 Green L, Edmonds N, Morgan L, et al. The Public Health Implications of Brexit in Wales: A Health Impact Assessment Approach. 2019. http://www.wales.nhs.uk/sitesplus/888/news/50275 (accessed November 17, 2020). to health and the NHS in the post-Brexit era. BMJ 2020; 369. DOI:10.1136/bmj.m2307. 